\title{
Population typing of the causal agent of cassava bacterial blight in the Eastern Plains of Colombia using two types of molecular markers
}

\author{
César A Trujillo ${ }^{1}$, Nathalia Arias-Rojas², Lucie Poulin², César A Medina ${ }^{2}$, Anibal Tapiero³, Silvia Restrepo ${ }^{1}$,
} Ralf Koebnik ${ }^{2}$ and Adriana J Bernal ${ }^{1 *}$

\begin{abstract}
Background: Molecular typing of pathogen populations is an important tool for the development of effective strategies for disease control. Diverse molecular markers have been used to characterize populations of Xanthomonas axonopodis pv. manihotis (Xam), the main bacterial pathogen of cassava. Recently, diversity and population dynamics of Xam in the Colombian Caribbean coast were estimated using AFLPs, where populations were found to be dynamic, diverse and with haplotypes unstable across time. Aiming to examine the current state of pathogen populations located in the Colombian Eastern Plains, we also used AFLP markers and we evaluated the usefulness of Variable Number Tandem Repeats (VNTRs) as new molecular markers for the study of Xam populations.

Results: The population analyses showed that AFLP and VNTR provide a detailed and congruent description of Xam populations from the Colombian Eastern Plains. These two typing strategies clearly separated strains from the Colombian Eastern Plains into distinct populations probably because of geographical distance. Although the majority of analyses were congruent between typing markers, fewer VNTRs were needed to detect a higher number of genetic populations of the pathogen as well as a higher genetic flow among sampled locations than those detected by AFLPs.

Conclusions: This study shows the advantages of VNTRs over AFLPs in the surveillance of pathogen populations and suggests the implementation of VNTRs in studies that involve large numbers of Xam isolates in order to obtain a more detailed overview of the pathogen to improve the strategies for disease control.
\end{abstract}

Keywords: Xanthomonas axonopodis pv. manihotis, Population dynamics, Molecular markers, Plant pathology

\section{Background}

In order to generate effective mechanisms for the control of plant diseases, it is crucial to gain insights into the diversity and population dynamics of plant pathogens $[1,2]$. Pathogens showing a high genotypic diversity are regarded as being harder to control, because plant resistance can be overcome by more suitable pathotypes [3]. Hence, the development of durable resistance becomes more challenging with this kind of pathogens. Factors such as the genetic flow between pathogen populations and processes that increase the

\footnotetext{
* Correspondence: abernal@uniandes.edu.co

'Laboratorio de Micología y Fitopatología Uniandes (LAMFU), Universidad de Los Andes, Bogotá, Colombia

Full list of author information is available at the end of the article
}

genetic changes of these populations may contribute to break the resistance in monocultures [3-5].

Xanthomonas axonopodis pv. manihotis (Xam) is the causal agent of cassava bacterial blight disease (CBB), the most important bacterial disease of cassava. The most common symptoms of CBB are angular leaf spots, stem exudates, cankers, blight, wilt and dieback [6,7]. $\mathrm{Xam}$ is an example of a pathogen that presents diverse degrees of variability in different geographical zones and interesting population processes, including genetic flow and instability of populations in different geographical regions [7-10]. Xam populations have been characterized in different countries in South America and Africa, starting in the 1980s. These studies showed that the South American populations were more diverse than those 
from Africa [9,11-14]. Particularly, Xam populations from Colombia were classified as highly diverse and showed significant levels of genetic flow between them, in spite of their distant geographical origins in the country $[8,9,14]$. In the 1990 s, Xam populations were mainly studied in three regions of Colombia: the Caribbean region, the Eastern Plains and the province of Cauca $[8,9,14]$. These studies showed that Xam populations from the Caribbean and Eastern Plains were dynamic and presented a higher genetic diversity when compared with populations from Cauca $[8,9,14]$. Recently, we monitored populations of the pathogen in the Caribbean region, where three cassava varieties are intensively and extensively cultivated. These studies were performed using AFLPs and sequences of genes coding for Type Three Effectors proteins (T3Es). In the Caribbean, we commonly found a lack of genetic differentiation among the sampled locations, as a result of potential genotype flow promoted by the exchange of propagative material infected with Xam. Additionally, we identified that Caribbean populations change rapidly over time, since it was already possible to establish a temporal differentiation compared to the populations characterized by Restrepo and collaborators in the 1990s [8,15]. Despite the relevance of a constant monitoring of pathogen populations, only those from the Caribbean have being recently studied [15]. However, it is pertinent to characterize populations outside of the studied regions and to establish their dynamics and to which extent those dynamics may have an impact on the crop.

A number of different molecular markers have been implemented for Xam population studies. These include Restriction Fragment Length polymorphisms (RFLPs), Enterobacterial Repetitive Intergenic Consensus-PCR (ERIC-PCR) and Amplified Fragment Length Polymorphisms (AFLPs) $[12,14,16]$. Nevertheless, the most useful markers for population typing of this pathogen are AFLPs $[8,10,16]$. This is due to their high discriminatory power, when compared to other types of markers previously used, such as RFLPs [16]. However, traditional AFLPs are a time-consuming technique. In addition, it is difficult to standardize the protocols between laboratories because band patterns are not easily coded and the process can become subjective $[17,18]$. Recently, other typing techniques have been developed to reduce the standardization time, as well as to reduce the time and cost required to obtain the results $[17,19]$. One of these techniques is based on the sequencing of Variable Number Tandem Repeat (VNTR) loci, which detect polymorphisms in tandem repeats in a given genome and have been important to obtain informative markers [20,21]. VNTRs were implemented more than a decade ago to characterize highly monomorphic human and animal pathogens such as Mycobacterium tuberculosis [22,23],
Bacillus anthracis [24] and Staphylococcus aureus [25]. More recently, VNTRs have been implemented to analyze the population genetics and diversity of plant pathogens such as Xylella fastidiosa [26], Xanthomonas citri pv. citri [27], Ralstonia solanacearum [28], and the bacterial rice pathogen Xanthomonas oryzae pv. oryzicola [29]. VNTRs have allowed to uncover variability that was not detected using other molecular markers [30,31]. An additional advantage of VNTRs compared to other typing techniques is the reduction in costs, which is given by the following factors: first of all, a DNA extraction procedure is often not required because VNTRs can be easily amplified from bacterial colonies. Secondly, the amplification and detection does not require specialized equipment and reagents [21]. Finally, the reduction in the sequencing cost allows the analyses of a higher number of loci and samples, with at a reasonably low cost $[17,19]$. All these advantages make VNTRs promising molecular markers to study populations of Xam when cost is a limiting factor and when the access to especialized laboratory equipment is restricted.

The aim of this study was to evaluate the diversity of current Xam populations in the Eastern Plains of Colombia using two types of neutral molecular markers. The Eastern Plains is the second most important region for cassava cultivation in Colombia. In contrast to the Caribbean cassava fields, Eastern Plains fields are considerably small and their growers are not commercially allied for trading of their produce. In this study, we isolated strains from cassava fields located at the provinces of Meta and Casanare, located at the Eastern Plains of Colombia, from 2011 to 2012. The collected isolates were typed using both AFLPs and VNTRs markers. This study highlights the usefulness of VNTR markers for characterizing populations of Xam. This study provides an updated distribution of distinct populations of Xam in the Eastern Plains of Colombia.

\section{Methods}

\section{Sampling and bacterial isolation}

Cassava crops in the Meta and Casanare provinces of Colombia were sampled from 2011 to 2012 (Figure 1). In Meta, local fields at La Libertad, Granada and Fuente de Oro were visited during 2011. In Casanare, fields near Orocué were sampled in 2012. Sampling was conducted in diagonal transects in three to four fields in each location. Leaves with characteristic CBB symptoms were collected for bacterial isolation. The number of collected samples was dependent on the disease incidence in each field.

For isolation of the bacterium, a $1 \mathrm{~cm}$-diameter leaf disk with infected and healthy tissue was obtained from each sample. The disk was disinfected with $1 \%$ hypochlorite and washed in sterile water three times. The 


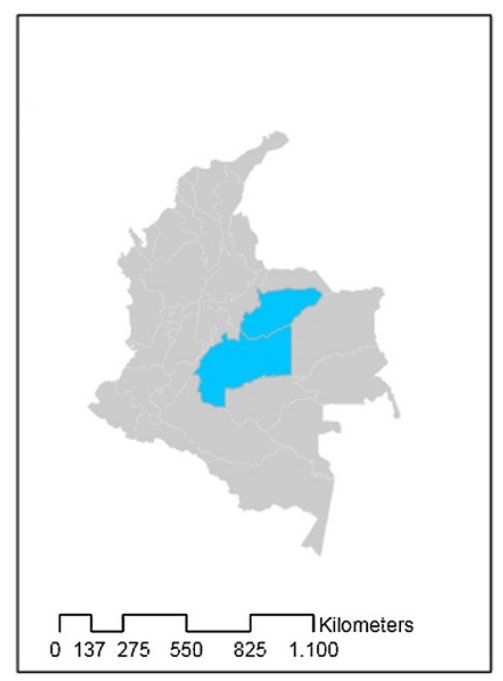

\section{SAMPLING ZONES}

LA LIBERTAD

GRANADA

GRANADA

FUENTE DE ORO

OROCUÉ

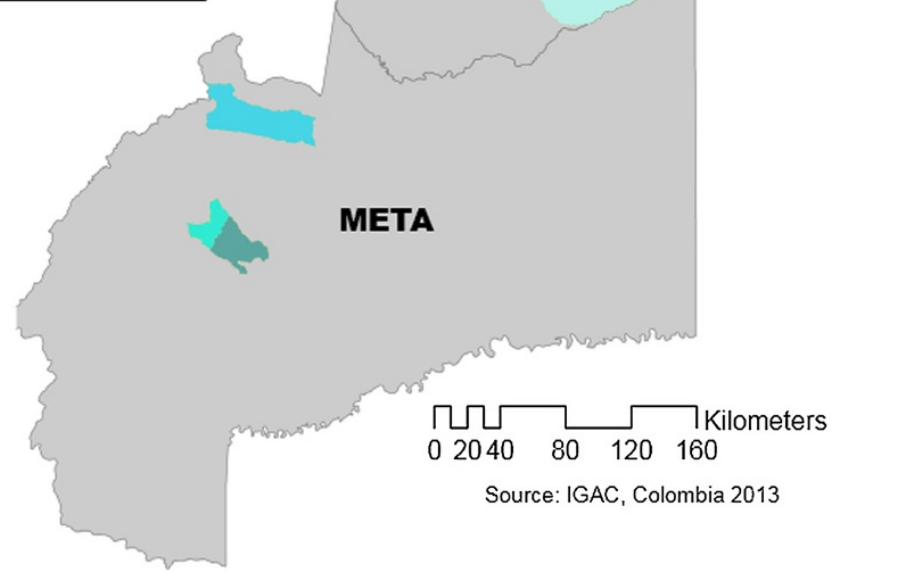

Figure 1 Sampling zones in the Eastern Plains of Colombia. Sampling zones were selected between provinces of Meta and Casanare. Shaded areas in the map represent sampled locations.

tissue was ground in $200 \mu \mathrm{l}$ of $10 \mathrm{mM} \mathrm{MgCl}_{2}$ and two 1:10 serial dilutions were performed. A total of $100 \mu \mathrm{l}$ of each dilution were plated onto LPGA medium (5 g yeast extract, $5 \mathrm{~g}$ dextrose, $5 \mathrm{~g}$ Peptone and $15 \mathrm{~g}$ agar were used per liter of distilled water) and then incubated at $28^{\circ} \mathrm{C}$ for $48 \mathrm{~h}$. White, viscous bacterial colonies, typical of Xam were found in high populations in all plates coming from symptomatic tissue. These were confirmed as Xam using primers directed to the $\mathrm{C}$-terminus of the gene coding for PthB, now called TALE1 $1_{\text {Xam }}$ [32] (Additional file 1), which is located in the plasmid $\mathrm{p} 44$. This region is widely distributed in Xam strains and it has been implemented for Xam identification [33]. A single colony from each sample was selected to be preserved in $30 \%$ glycerol at $-80^{\circ} \mathrm{C}$. In addition, ten $\mathrm{Xam}$ strains, which represented the genetic diversity of the pathogen in the 1990s in the Colombian Eastern Plains, were used as reference strains. Reference strains were kindly provided by Dr. Valérie Verdier from IRD (Institut de recherche pour le développement, Montpellier, France).

\section{DNA extraction and amplification}

Xam isolates were grown overnight in $5 \mathrm{ml}$ of liquid Phi $(\Phi)$ medium (10 g yeast extract, $5 \mathrm{~g}$ dextrose and $5 \mathrm{~g}$ Casaminoacids per liter of distilled water) at $220 \mathrm{rpm}$ and $28^{\circ} \mathrm{C}$. Total DNA was obtained using the PureLink ${ }^{\mathrm{Tu}}$ genomic DNA mini kit according to the manufacturer instructions (Invitrogen, Carlsbad, CA, USA). The DNA quality was checked in $0.8 \%$ agarose gel electrophoresis, and it was quantified using a NanoDrop spectophotometer ND1000 (Nanodrop Technologies, Wilmington, DE, USA).

\section{Genotyping with AFLPs}

Two hundred nanograms of total DNA from each isolate were digested with the restriction enzymes EcoRI and MseI to generate the AFLPs [34], using the AFLPs Core Kit for microorganisms from Invitrogen Corporation, as recommended by the manufacturer (Invitrogen, CA, USA). The following modifications were implemented for the current study: each restricted product was 
diluted 1:10 and used as template for non-selective PCR amplification with primers $M s e \mathrm{I}+0 / E c o R I+0$. The thermal profile used was: 20 cycles at $94^{\circ} \mathrm{C}$ for $30 \mathrm{sec} ; 56^{\circ} \mathrm{C}$ for $60 \mathrm{sec} ; 72^{\circ} \mathrm{C}$ for $60 \mathrm{sec}$. A 1:25 dilution of the PCR product was used as template for the selective amplification with four primer combinations $(E c o R I+\mathrm{T} / M s e \mathrm{I}+\mathrm{T}, E c o \mathrm{RI}+\mathrm{T} /$ $M s e \mathrm{I}+\mathrm{A} \quad E c o R I+\mathrm{G} / M s e \mathrm{I}+\mathrm{A}$ and $E c o \mathrm{RI}+\mathrm{C} / M s e \mathrm{I}+\mathrm{A})$ (Additional file 1). The thermal profile for the selective amplifications was: one cycle at $94^{\circ} \mathrm{C}$ for $30 \mathrm{sec} ; 65^{\circ} \mathrm{C}$ for $30 \mathrm{sec}$; and $72^{\circ} \mathrm{C}$ for $60 \mathrm{sec}$, and 12 cycles with a touch-down in the annealing temperature of $0.7^{\circ} \mathrm{C}$ per cycle. Finally, 23 cycles were conducted at $94^{\circ} \mathrm{C}$ for $30 \mathrm{sec}, 56^{\circ} \mathrm{C}$ for $30 \mathrm{sec}$ and $72^{\circ} \mathrm{C}$ for $60 \mathrm{sec}$. Selectively amplified products were separated on $6 \%$ polyacrylamide gel (19:1 acrylamide:bisacrylamide; 7.5 M Urea; $1 \times$ TBE buffer) at $3000 \mathrm{~V}, 40 \mathrm{~mA}$ for 1 hour and 40 minutes on a vertical polyacrylamide electrophoresis apparatus. Every sample was run twice to verify AFLP reproducibility. AFLP bands were detected with silver staining. Polymorphic bands were then scored as either present (1) or absent (0) on a presence/absence matrix. Only strong bands were included in the matrix.

\section{Selection and evaluation of VNTRs}

VNTR loci were selected according to the Hunter-Gaston discriminatory index (HGDI) [35], which was previously evaluated among 65 genomes of $\mathrm{Xam}$ [36]. Loci with HGDI scores higher than 0.6, such as, XaG1_02, XaG1_29, XaG2_52, XaG1_67 and XaG1_73 were selected to be amplified from Xam isolates. The primers used for PCR amplification were those reported by Arrieta et al., [36].

VNTR loci were amplified either from genomic DNA or from a fresh bacterial colony. Each PCR reaction contained 10-50 ng of genomic DNA, $2.5 \mathrm{mM} \mathrm{MgCl}_{2}$, $3 \mathrm{mM}$ PCR primers, $1.3 \mathrm{mM}$ dNTPs and 1 unit of Taq DNA polymerase (Fermentas, USA). Thermal profile was conducted as follows: $3 \mathrm{~min}$ at $95^{\circ} \mathrm{C}, 35$ cycles consisting of $20 \mathrm{sec}$ at $95^{\circ} \mathrm{C}, 30 \mathrm{sec}$ at $52-58^{\circ} \mathrm{C}$, and $60 \mathrm{sec}$ at $72^{\circ} \mathrm{C}$, with a final extension step at $72^{\circ} \mathrm{C}$ for $10 \mathrm{~min}$. When a bacterial colony was used as the direct source of the template, an additional step of $95^{\circ} \mathrm{C}$ for $10 \mathrm{~min}$ at the beginning of the thermal profile was added. Amplified products were separated on $1 \%$ agarose gels and then sequenced using the primers listed in the Additional file 1.

Sequences were aligned using MUSCLE [37] and then numbers of complete repeats were calculated from multiple alignments. The number of repeats at each locus for every strain was recorded in a matrix.

\section{Data analysis}

Molecular Variance Analysis (AMOVA) was conducted to determine genetic differentiation among sampled provinces estimating the genetic differentiation among population value $\left(\Phi_{\mathrm{PT}}\right)$ with 1000 permutations using
GenAlEx 6.5 [38]. Then, genetic Euclidean distances among sampled locations were calculated in GenoDive $2.0 \mathrm{~b} 20$ [39]. To visualize the dissimilarities among the isolates, a Principal Coordinates Analysis (PCoA) was also carried out using GenAlEx 6.5 [38]. Once the dissimilarities among isolates were confirmed, isolates were clustered in an unrooted distance tree with the Neighbor-Joining algorithm in SplitsTree version 4.12.3 [40]. Branch supports were determined running 1000 bootstrap replicates. Then, current isolates were assigned into genetic populations using a clustering algorithm based on Bayesian model in STRUCTURE 2.3.3 [41] without prior population information. Genetic clusters of the isolates were generated with independent allele frequencies and five thousand replicates during burning period and 100.000 Monte Carlo Markov chain (MCMC) iterations. Iterations were performed from 1 to 10 clusters (K) and then the optimal number of clusters was determined according to Evanno et al. [42]. $\mathrm{F}_{\mathrm{ST}}$ values [43] from the optimal number of clusters were recorded. A Mantel test was performed with 999 permutations using GenAlEx 6.5 [38] to confirm if the clustering pattern was correlated with geographical distances of sampled locations.

Isolates were then classified into haplotypes, which were established with an infinite allele model and a threshold of 0 using GenoDive 2.0b20 [39]. The clonal diversity at each location was estimated implementing the corrected Nei and Shannon indices in GenoDive 2.0b20. Assigned haplotypes were split in a Minimum Spanning Network using BioNumerics software (version 7.1) created by Applied Maths NV (Available from http://www. applied-maths.com).

\section{Results}

\section{A large number of isolates was obtained from cassava} producing areas in the Eastern Plains of Colombia

A total of 101 isolates were collected at four locations in the Eastern Plains of Colombia. From these, 47 isolates were collected in La Libertad (Meta) from an experimental field that contained 96 representative cassava accessions from the Eastern Plains. The experimental field was visited with permission of the International Center for Tropical Agriculture (CIAT). In contrast, other sampled locations presented one or a maximum of two cassava varieties per field. Commercial field crops at Granada and Fuente de Oro (Meta) presented a comparatively low number of samples with typical CBB symptoms. Only three isolates were obtained from Granada and one isolate was obtained from Fuente de Oro. In addition, $50 \mathrm{Xam}$ isolates were obtained from four fields located in Orocué in the province of Casanare. Samples collected in Orocué came from small plots where cassava is cultivated for self-consumption of smallholder farmers, in contrast to the fields visited in the other locations. 


\section{AFLP and VNTR markers showed reproducible band patterns}

One-hundred and one isolates and ten reference strains were characterized by both AFLP and VNTR markers. The characterization with AFLPs was performed with four combinations of selective primer pairs. AFLP band patterns obtained with selective amplifications were clear to read after detection with silver staining. A total of 57 polymorphic bands were generated when primer combinations $E c o \mathrm{RI}+\mathrm{T} / M s e \mathrm{I}+\mathrm{T}, \quad E c o \mathrm{RI}+\mathrm{T} / M s e \mathrm{I}+\mathrm{A}$ and $E c o R I+C / M s e I+A$ were used. Primer combination $E c o R I+G / M s e I+A$ did not produce polymorphic bands among the evaluated isolates. AFLP selective amplifications were run twice for each isolate. Band patterns were consistent between replicates.

Xam isolates were also characterized using five VNTR loci. PCR amplicons of VNTRs were strong and highly reproducible. Sequencing of VNTR loci showed that the number of alleles per locus ranged from 7 to 17 (Table 1). Locus G1_29 was the most polymorphic VNTR with 17 different alleles, ranging from 1 to 23 repeats (Table 1 ). The data sets supporting the results of this article are available in the GenBank database (Accession numbers XaG1_02: KJ736838 - KJ736944; XaG1_29: KJ736945 - KJ737053; XaG2_52: KJ737163 - KJ737268; XaG1_67: KJ737269 KJ737369; XaG1_73: KJ737054 - KJ737162) and in the Dryad Digital Repository: http://doi.org/10.5061/dryad.t173v.

\section{Xam populations presented a genetic differentiation among locations in the Eastern Plains}

In order to confirm if there was genetic differentiation among sampled locations, an AMOVA was conducted. $\Phi_{\mathrm{PT}}$ values showed a statistically significant genetic differentiation between each pair of locations (Table 2). The differentiation was evidenced using both types of molecular markers. Similar proportions of genetic variation were obtained when comparisons between locations and within locations were performed using AFLPs. However, $80 \%$ of the genetic variation was distributed within the sampled locations when isolates were characterized by VNTRs. Furthermore, PCoA analysis showed that AFLPs allowed the detection of a more contrasting differentiation among isolates with different geographical origins (Figure 2). VNTRs also permitted an evident differentiation, but a partial overlapping of isolates from La Libertad and Orocué was observed. However, approximately $75 \%$ of the variation among isolates was explained with the first three coordinates of the analysis for both markers (Figure 2).

The genetic population structure of Xam was correlated with the geographical origin of isolates in the Eastern

\section{Plains of Colombia}

Distance trees were constructed using AFLP and VNTR data to determine how genetic distances were distributed among current isolates and reference strains (Figure 3). Tree topologies showed a generalized clustering according to geographical origin of the isolates, but the composition of inner clusters changed between techniques. In most of the cases, the global behavior of isolates across the topologies was comparable, with only few exceptions. One of them was a small group of isolates from Orocué, which clustered together with isolates from La Libertad (Meta) when VNTRs were used. This grouping was not observed when AFLPs were used. Interestingly, both techniques revealed that most of the reference strains tended to cluster with isolates from Orocué (Casanare) and La Libertad (Meta), which suggested that those strains presented a similar proportion of shared characters with strains coming from these two locations. This is supported by the fact that similar Euclidean distances were obtained when reference strains were compared to the isolates from La Libertad and to the isolates from Orocué (data not shown).

We then evaluated if there were distinguishable genetic clusters of the pathogen in the Eastern Plains region. When isolates were assigned to estimate genetic clusters using AFLP markers, they were grouped in two welldifferentiated genetic clusters (Figure 4A). Each genetic cluster was mainly conformed by isolates from the same location, suggesting that geographical distances influenced the designation of clusters. This observation was corroborated with a Mantel test that showed a positive correlation between genetic and geographical distances $\left(R^{2}=0.9302\right)$. On the other hand, five genetic clusters were estimated when isolates were characterized using VNTRs (Figure 4B). In the same way, K clusters grouped according to the origin of isolates but this was less

Table 1 Characteristics of VNTR loci evaluated in Xam isolates from the Colombian Eastern Plains

\begin{tabular}{cccccc}
\hline VNTR locus & Repeat & Number of different alleles & Range of allele repetitions & Dominant alleles & HGDI index \\
\hline G1_02 & TCCCCAT & 7 & $1-9$ & 48 & 0.7019 \\
G1_29 & ATCCCGA & 17 & $1-23$ & 5 & 0.858 \\
G1_52 & CCGCCACAACGCA & 7 & $4-10$ & 6 \\
G1_67 & CGACAC & 14 & $10-26$ & 1626 \\
G1_73 & GGTCAT & 8 & $5-12$ & 679 \\
\hline
\end{tabular}

VNTR loci were selected according to discriminant index reported by Arrieta and collaborators [36]. 
Table 2 Genetic variance among sampled locations in the Eastern Plains using AFLP and VNTR markers

\begin{tabular}{|c|c|c|c|c|c|c|c|c|c|}
\hline \multirow{2}{*}{\multicolumn{2}{|c|}{ Location pair }} & \multirow{2}{*}{\multicolumn{2}{|c|}{ Number of isolates }} & \multicolumn{6}{|c|}{ Molecular marker } \\
\hline & & & & \multicolumn{3}{|c|}{ AFLP } & \multicolumn{3}{|c|}{ VNTR } \\
\hline Loc. 1 & Loc. 2 & Loc. 1 & Loc. 2 & $\Phi_{\mathrm{PT}}$ & $\operatorname{Lin} \Phi_{P T}$ & p-value & $\Phi_{\mathrm{PT}}$ & $\operatorname{Lin} \Phi_{P T}$ & $\mathrm{p}$-value \\
\hline La Libertad & Granada & 47 & 3 & 0.393 & 0.649 & $0.001^{*}$ & 0.245 & 0.324 & $0.003^{*}$ \\
\hline La Libertad & Orocué & 47 & 50 & 0.520 & 1.082 & $0.001^{*}$ & 0.192 & 0.238 & $0.001^{*}$ \\
\hline Granada & Orocué & 3 & 50 & 0.623 & 1.649 & $0.001^{*}$ & 0.196 & 0.244 & $0.021^{*}$ \\
\hline
\end{tabular}

* Statistically significant $(p>0.05)$.

$\left(\Phi_{\mathrm{PT}}\right)$ : genetic differentiation among population.

$\left(\mathrm{Lin} \Phi_{\mathrm{PT}}\right)$ : Linearized genetic differentiation among population.

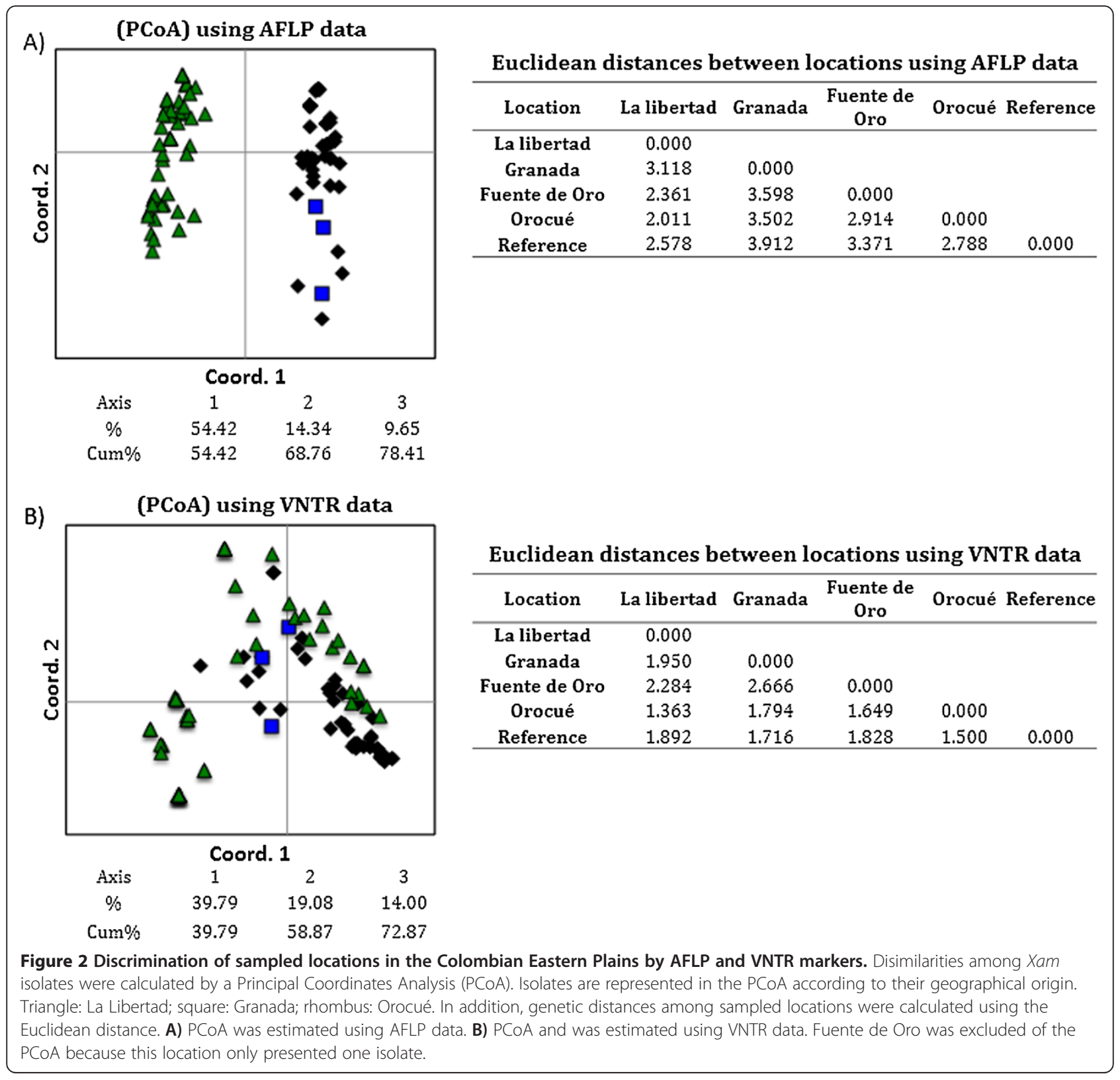



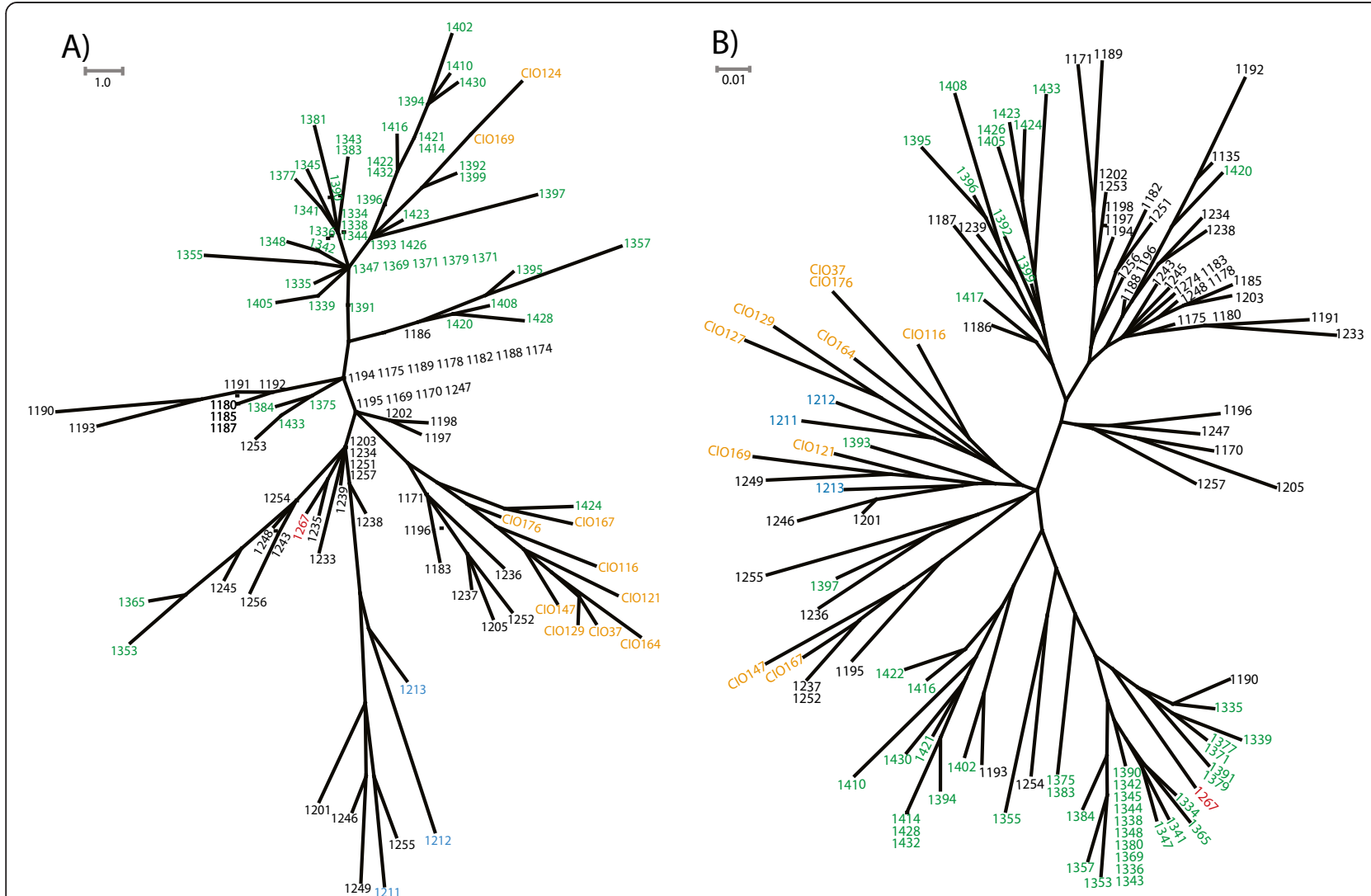

Figure 3 Distance trees generated with AFLP and VNTR data from isolates collected in Casanare and Meta. Unrooted distance trees were constructed with the Neighbor-Joining algorithm in SplitsTree version 4.12.3 A) Distance tree was constructed using four selective pairs of primers to amplify AFLP markers. B) Distance tree constructed using five VNTR loci. La Libertad: black; Granada: blue; Fuente de Oro: red; Orocué: green and reference strains: orange.

evident than for the clusters generated by AFLPs. The fact that VNTRs detected new clusters is suggesting that those markers were able to distinguish an encrypted population structure that was not detected by AFLPs. Similarly to what was observed with AFLPs, VNTRs detected a genetic structure correlated with geographical location. The Mantel test suggested a positive correlation between genetic and geographical distances $\left(\mathrm{R}^{2}=\right.$ 0.2666), however this correlation was not as evident as the one estimated using the AFLP markers. $\mathrm{F}_{\mathrm{ST}}$ values from the populations estimated using both techniques were compared. $\mathrm{F}_{\mathrm{ST}}$ values of the five populations obtained for the VNTR analysis were lower than the $\mathrm{F}_{\mathrm{ST}}$ values from the populations generated with the AFLP analysis, indicating that VNTRs detected a higher genetic flow between populations.

The diversity of Xam haplotypes in the Eastern Plains was comparable when the two types of molecular markers were implemented

An analysis of haplotype assignment was conducted to determine the number and distribution of haplotypes among sampled locations. A haplotype was defined with a 100\% similarity threshold for both AFLP and VNTR loci. Both approaches generated a highly similar number of haplotypes for each sampled location and for reference strains (Table 3). In addition, both techniques allowed the distinction of a high number of haplotypes, with AFLPs and VNTRs detecting 86 and 87 haplotypes out of 111 isolates, respectively. Consequently, the clonal diversity at each location was considerably high and comparable for both approaches (Table 3). However, high diversity values were most probably the result of the stringency in the assignment of haplotypes $(100 \%$ similarity between isolates).

Haplotypes were divided in a minimum spanning network to visualize the connectivity between them (Figure 5). These networks evidenced that most haplotypes are grouped according to geographic location, which was expected from the Mantel test results described above. However, VNTR haplotypes from Orocué (Casanare) presented larger genetic distances among them than to haplotypes from La Libertad (Meta). This result suggests that VNTR amplification was more discriminating 


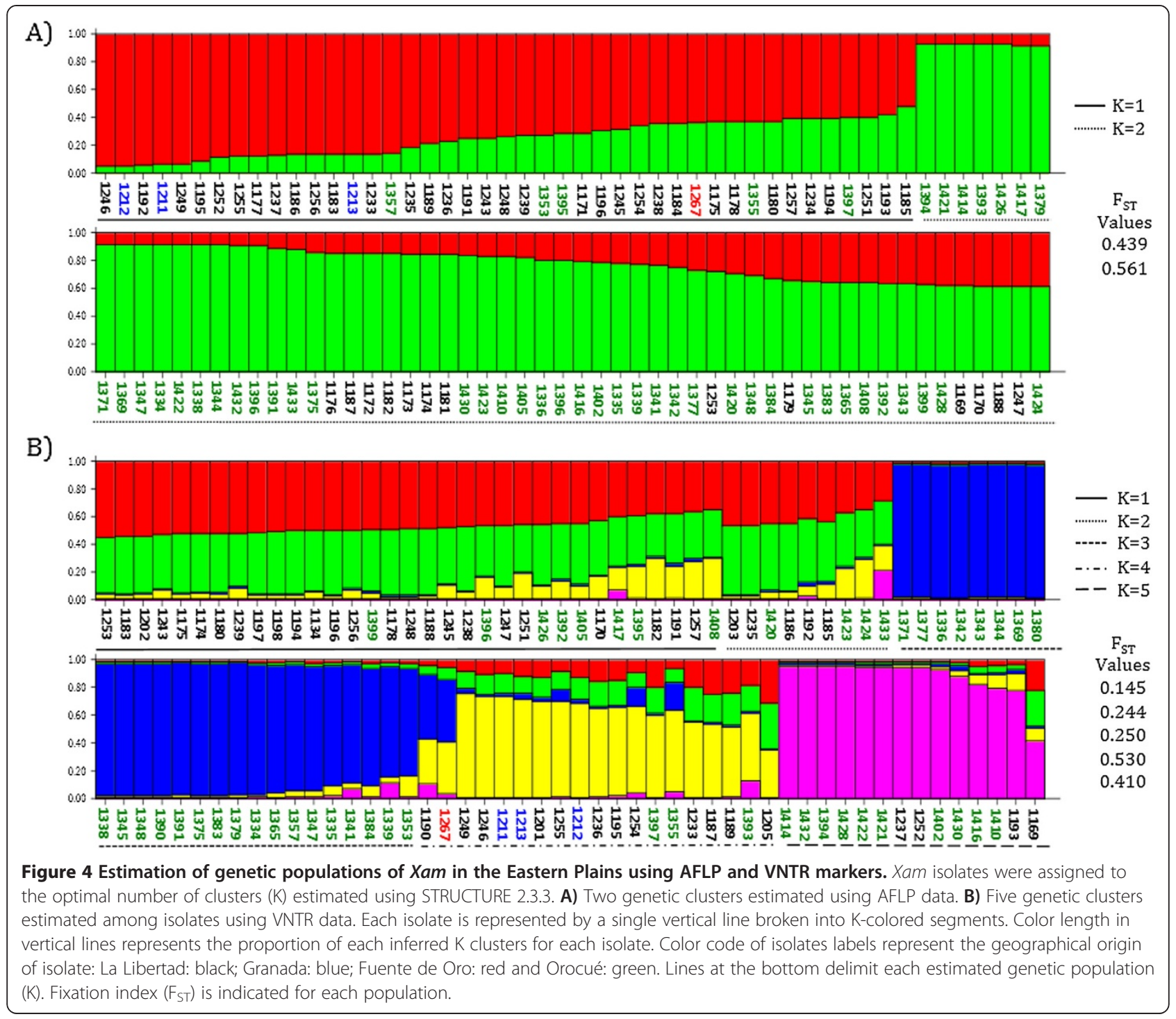

for haplotypes contained in the same geographical area. Sometimes, this haplotype discrimination was considerably notorious. For example, haplotypes from the same location, such as Granada (Figure 5), were displayed far from each other in the networks. Finally, it was evident that haplotypes from the reference strains showed a remarkable distance from most of the haplotypes assigned to current Xam isolates, evidencing a potential temporal differentiation. This was observed with both types of markers (Figure 5).

\section{Discussion}

In order to determine the current state of populations of Xam and the diversity of this pathogen in the Colombian Eastern Plains, Xam isolates were characterized using two types of molecular markers. AFLPs were the first molecular markers used for the assessment of diversity in this pathogen and have also been implemented in recent population studies $[10,15]$. The second type of molecular marker was VNTR, which have recently been proposed as promising markers for typing populations of this pathogen [36] but had not been evaluated for this purpose. Here, we present a complete comparison of population analyses obtained with both types of markers and report the usefulness and benefits of these techniques in the characterization of Xam populations.

Sampling for this study was focused on four locations in two provinces of the Eastern Plains of Colombia. Although the sampling effort was equal for each location, it was not possible to obtain comparable amounts of samples from each sampled area. For instance, 96\% of the total isolates were collected in La Libertad (Meta) and Orocué (Casanare). In contrast, Fuente de Oro and Granada were the source of only a few samples for this study. The difference in the number of isolates was due to great differences in disease incidence among 
Table 3 Assignment of haplotypes and clonal diversity in the Colombian Eastern Plains

\begin{tabular}{|c|c|c|c|c|c|c|}
\hline Molecular marker & Location & No. isolates & No. haplotypes & $\begin{array}{l}\text { No. repeted } \\
\text { haplotypes }\end{array}$ & $\begin{array}{c}\text { Corrected Nei's index } \\
\text { Div_obs }\end{array}$ & $\begin{array}{c}\text { Corrected Shannon's index } \\
\text { Div_obs }\end{array}$ \\
\hline \multirow{6}{*}{ AFLP } & La Libertad & 47 & 33 & 4 & $0.967^{*}$ & $1.802^{*}$ \\
\hline & Granada & 3 & 3 & - & 1.000 & nan \\
\hline & Fuente de Oro & 1 & 1 & - & nan & nan \\
\hline & Orocué & 50 & 39 & 7 & 1.000 & nan \\
\hline & Reference & 10 & 10 & - & 0.985 & $2.001^{*}$ \\
\hline & Overall & 111 & 86 & 13 & $0.991^{*}$ & $2.331^{*}$ \\
\hline \multirow{6}{*}{ VNTR } & La Libertad & 47 & 39 & 6 & $0.988^{*}$ & $2.163^{*}$ \\
\hline & Granada & 3 & 3 & - & 1.000 & nan \\
\hline & Fuente de Oro & 1 & 1 & - & nan & nan \\
\hline & Orocué & 50 & 34 & 6 & $0.940^{*}$ & $1.783^{*}$ \\
\hline & Reference & 10 & 10 & - & 0.978 & $1.653^{*}$ \\
\hline & Overall & 111 & 87 & 12 & $0.984^{*}$ & $2.356^{*}$ \\
\hline
\end{tabular}

*Statistically significance $(p>0.05)$.

nan: non calculated value because all isolates present a different haplotype. 


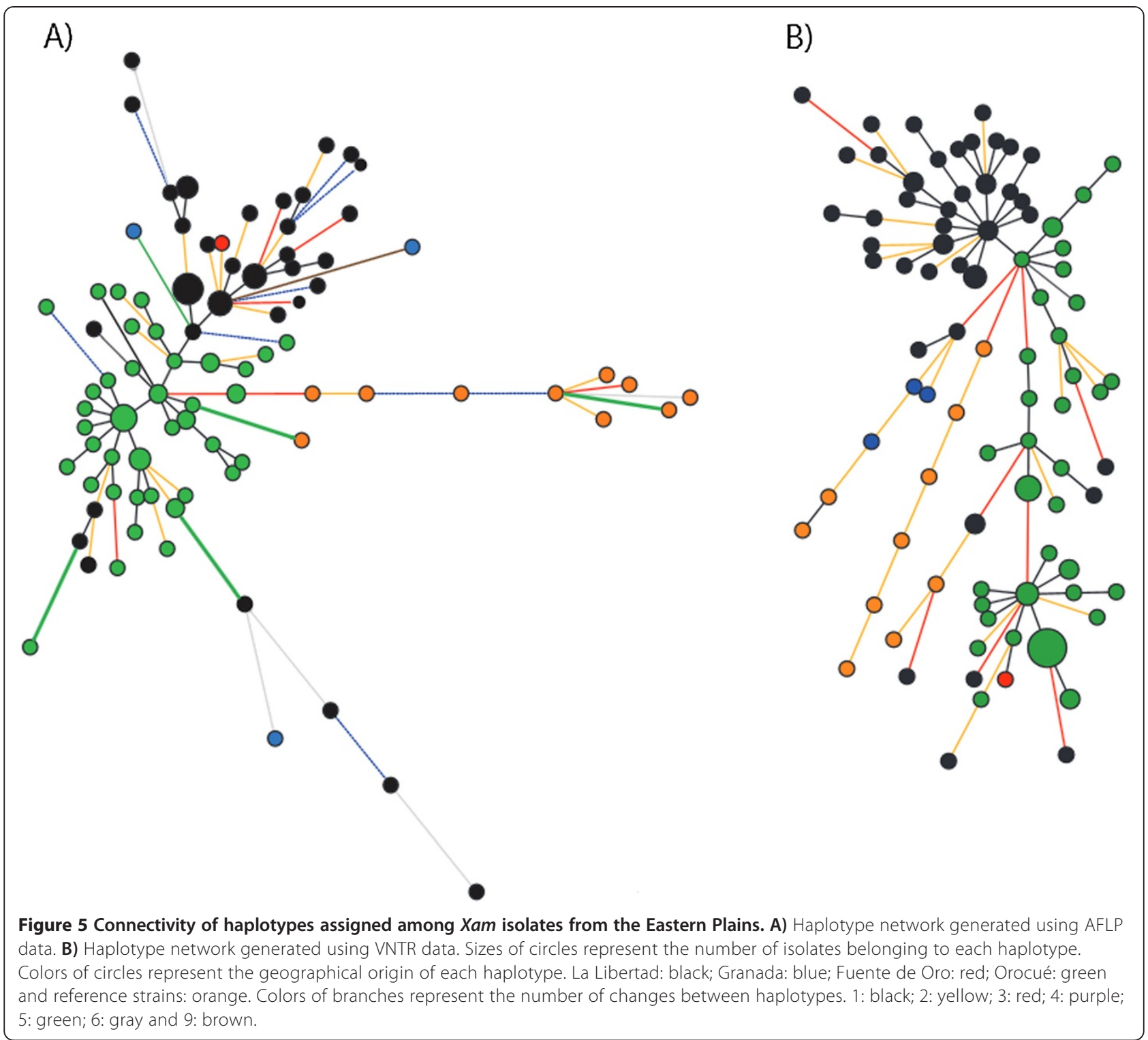

locations. In contrast to La Libertad and Orocué, cassava fields in Granada and Fuente de Oro are constantly rotated by growers or substituted by other types of crops and this could have contributed to a reduction in the incidence of $\mathrm{CBB}$ in these locations.

In spite of the difference in the number of samples, we could easily conclude that VNTRs and AFLPs provide congruent results for Xam populations. This is supported by several observations. First, both techniques were able to genetically differentiate the populations of Xam between sampled locations. Second, global clustering patterns were constant in both types of markers. For instance, clustering in distance trees and haplotype networks was clearly defined by the geographical origin of isolates, although AFLPs displayed a better geographical clustering (Figure 3). Third, the distribution of haplotypes from Granada (Meta) was congruent between both techniques used. Both of them displayed Granada haplotypes very distant as shown in the Figure 5 . This behavior is in contrast to what was expected. Cultural practices such as crop rotation, which is intensively implemented in this location, should have generated a genetic drift event that could have led to a reduction in pathogen diversity [3]. However, the instability of cassava fields due to intensive crop rotation and the reduced number of plants with $\mathrm{CBB}$ symptoms in Granada did not allow the constant tracing of the pathogen in order to explain the attained behavior of these isolates. Fourth, a congruent behavior was also observed for the reference strains, which were almost completely grouped in the distance trees and 
networks from both analyses (Figures 3, 4 and 5). This suggests a temporal differentiation of Xam populations, a process that is occurring even in short periods of time, as was evidenced in the recently characterized Caribbean populations and also with populations from the 1990s $[9,16]$.

There were also contrasting results when analyses from AFLPs and VNTRs were compared. For example, although isolates were clustered according to their geographical origin, the composition of inner clusters changed between techniques. This discrepancy could be explained by the fact that each type of marker evaluates polymorphisms at different scales. AFLPs evaluate differences distributed along the whole genome and those differences must be located in recognition sites for restriction enzymes [34]. Detection of polymorphisms in AFLPs is highly influenced by the combination of restriction enzymes and selective primers used in this technique [44]. In contrast, VNTRs evaluate the variation in restricted genomic areas, where short tandem repeats are located. These repetitive genomic regions promote the Slipped-strand mispairing phenomenon during DNA replication, producing a change in the number of repetitive elements and increasing the mutation rate in a specific locus $[21,45,46]$. In addition, VNTRs could present homoplasy events that could be influencing the clustering process. However, the use of reasonable number of VNTR loci reduces this effect [47]. Because both AFLPs and VNTRs are evolving at different rates and each detects variation at different genomic scales, it is not surprising that the pattern of composition of the inner clusters could differ, as observed at the Figure 3.

Additionally, AFLPs and VNTRs showed discrepancies when the optimal number of genetic clusters was estimated. The optimal $\mathrm{K}$ clusters for VNTRs $(\mathrm{k}=5)$ was larger than that for AFLPs $(k=2)$. This finding suggests that VNTRs were able to detect a more detailed structuring of Xam population that was not detected by AFLPs. However, three of the genetic clusters generated by VNTRs presented considerably lower $\mathrm{F}_{\mathrm{ST}}$ indices indicating a high genetic flow among them (Figure 4). These genetic clusters with a high genetic flow could be considered as part of a bigger population when the other molecular marker is implemented. In our case, STRUCTURE could assume that those three genetic clusters with high genetic flow could be encrypted when the clusters were estimated using AFLP markers. On the other hand, although $\mathrm{K}$ clusters presented considerable differences in $\mathrm{F}_{\mathrm{ST}}$ values, both techniques confirmed the genetic flow between geographically distant locations, such as La Libertad and Orocué, which are separated by approximately $250 \mathrm{~km}$. This process of genetic flow was also documented between distant locations even when locations were located in very distant regions of Colombia. For example, between the Caribbean and the Eastern Plains regions, there is a geographic distance of more than $500 \mathrm{~km}[8,14,15]$.

If we compare the current populations from the Caribbean and the Eastern Plains, it is evident that the pathogen is more diverse in the Caribbean. A total of 57 AFLP haplotypes were detected among 160 isolates from the Caribbean region, when using $80 \%$ similarity as a threshold. [15]. In the Eastern Plains region, 28 haplotypes were detected among 111 isolates, with haplotype assignment at $80 \%$ similarity (data not shown). These observations are in contrast to what was reported for Colombian populations in the nineties, where the pathogen was more diverse in the Eastern Plains than in the Caribbean region $[8,9,14]$. This could be related to the limited number of samples collected in the Eastern Plains because of the low CBB incidence encountered in some of the sampled locations at this region. The decrease in incidence could be explained by the reduction in the area dedicated to cassava cultivation in Meta in recent years [48].

In contrast to the locations at the Eastern Plains, most of the Caribbean populations did not display a geographically-dependent genetic differentiation [15]. These differences could be a consequence of the mode of cultivation of cassava in the two regions. Cassava cropping in the Caribbean is considerably more intensive and extensive than it is in the Eastern Plains [48], something that could reduce geographical isolation of Xam populations. In contrast, the geographical differentiation detected at the Eastern Plains populations could also be associated with the fact that growers in Orocué are indigenous people who do not move over large geographical distances. This phenomenon could reduce the exchange of propagative material infected with Xam, hence enhancing genetic differentiation between Eastern Plain locations.

In this study, we were able to assess the usefulness of VNTRs for the study of Xam populations. Remarkably, only 5 VNTR loci offered a very similar panorama of the pathogen populations to that obtained by 57 AFLP loci. This finding is relevant for further studies on the population dynamics of Xam, because VNTR markers provide a faster and less expensive characterization of bacterial isolates, as has been reported for several pathogenic microorganisms $[22,24,25,49]$. The fact that amplification of VNTRs requires neither a complex DNA extraction procedure, nor compounds different from those used in a regular PCR, makes VNTRs ideal when a large number of isolates are considered and when funding is limiting. Moreover, sharing information between laboratories would be considerably more straightforward with VNTRs than with AFLPs, because results from VNTRs 
can be more easily coded [17]. For future Xam survey studies we recommend the use of VNTRs. The rising number of sequenced genomes available nowadays, provides an additional advantage to identify new VNTR loci, hence improving the characterization of several pathogens [19,21,50,51]. Recently, 65 partial genomes of Xam strains have been released [52], providing a valuable opportunity to detect VNTRs with high discriminatory power. Currently, we are focusing on the prediction and evaluation of new VNTR loci into a core of the representative Xam strains using the information obtained from the 65 draft genome sequences. Our goal is to obtain a small sets of VNTRs with a high discriminatory power, aiming to implement them in studies that involve a large number of isolates to provide a more accurate description of evolving processes taking place in Xam populations.

\section{Conclusions}

This study represents the first attempt to type populations of Xam using VNTRs as molecular markers. Here we demonstrated that a small number of VNTR loci could offer a similar panorama of the status of the pathogen to that offered by AFLPs markers. Because VNTRs represent a fast and simple tool to type Xam populations, their implementation will allow a constant and adequate surveillance of the pathogen, which could provide information to improve the efficiency of strategies for disease control, such as the deployment of resistant varieties.

\section{Availability of supporting data}

The data sets supporting the results of this article are available in the Dryad Digital Repository: http://doi.org/ 10.5061/dryad.t173v.

DNA sequences are available in Genbank database: (Accession numbers XaG1_02: KJ736838 - KJ736944; XaG1_29: KJ736945 - KJ737053; XaG2_52: KJ737163 KJ737268; XaG1_67: KJ737269 - KJ737369; XaG1_73: KJ737054 - KJ737162).

\section{Ethics statement}

This study did not involve any human material, or human data. No experimental procedure was performed in vertebrate or invertebrate animals for the development of this research.

\section{Additional file}

Additional file 1: Primers used for the AFLP amplification and VNTR amplification and sequencing.

\section{Competing interests}

The authors declare that they have no competing interests.

\section{Authors' contributions}

CT was involved in the conception and design of the study, sampling, bacterial isolation, molecular characterization using AFLPs and VNTRs, data analyses and who wrote the manuscript. NAR performed DNA extraction, the evaluation of 3 VNTR loci, VNTR data analyses and drafting of the manuscript. LP contributed in the evaluation 3 VNTR loci, VNTR data analyses and drafting of the manuscript. CM carried the sampling and data acquisition. AT participated in the data acquisition and revised the content of the manuscript. SR was involved in the conception and design of the study, drafting and revising the manuscript. RK was involved in the conception and design of the study and the design of the VNTR strategy. AB participated in the conception and design of the project, funding acquisition, editing and revisiting of manuscript. All authors read and approved the final manuscript.

\section{Acknowledgements}

The authors would like to thank to the Faculty of Sciences from Universidad de los Andes, the Evaluation-orientation de la Coopération Scientifique (ECOS project No. C11A02) and the National Science Foundation/BREAD (Basic Research to Enable Agricultural Development) grant (Award 0965418) for funding this study. We also thank the International Center for Tropical Agriculture (CIAT) for enabling the sampling at their experimental cassava field located in Corpoica (La Libertad, Meta). We also thank Daniela Osorio for help in the edition of manuscript style. Finally we thank Estefanía Luengas for help in figure editing.

\section{Author details}

'Laboratorio de Micología y Fitopatología Uniandes (LAMFU), Universidad de Los Andes, Bogotá, Colombia. Institut de Recherche pour le Développement (IRD), UMR Résistance des Plantes aux Bioaggresseurs, Montpellier, France. ${ }^{3}$ Corporación Colombiana de Investigación Agropecuaria (CORPOICA), La Libertad, Villavicencio, Colombia.

Received: 8 October 2013 Accepted: 10 June 2014

Published: 19 June 2014

\section{References}

1. Lannou C, Hubert P, Gimeno C: Competition and interactions among stripe rust pathotypes in wheat-cultivar mixtures. Plant Pathol 2005, 54(5):699-712.

2. Mundt CC: Use of multiline cultivars and cultivar mixtures for disease management. Annu Rev Phytopathol 2002, 40:381-410.

3. McDonald BA, Linde C: Pathogen population genetics, evolutionary potential, and durable resistance. Annu Rev Phytopathol 2002, 40:349-379.

4. Stukenbrock EH, McDonald BA: The origins of plant pathogens in agro-ecosystems. Annu Rev Phytopathol 2008, 46:75-100.

5. Barrett LG, Thrall PH, Burdon JJ, Linde CC: Life history determines genetic structure and evolutionary potential of host-parasite interactions. Trends Ecol Evol 2008, 23(12):678-685.

6. Maraite $\mathrm{H}$ : Xanthomonas campestris pathovars on cassava: cause of bacterial blight and bacterial necrosis. In Xanthomonas. Edited by Swings JG, Civerolo EL. London: Chapman and Hall; 1993:18-24.

7. Lozano J: Cassava bacterial blight: a manageable disease. Plant Dis 1986, 70:1089-1093.

8. Restrepo S, Velez CM, Duque MC, Verdier V: Genetic structure and population dynamics of Xanthomonas axonopodis pv. manihotis in Colombia from 1995 to 1999. Appl Environ Microb 2004, 70(1):255-261.

9. Restrepo $S$, Velez CM, Verdier V: Measuring the genetic diversity of Xanthomonas axonopodis pv. manihotis within different fields in Colombia. Phytopathology 2000, 90(7):683-690.

10. Ogunjobi AA, Fagade OE, Dixon AG: Comparative analysis of genetic variation among Xanthomonas axonopodis pv manihotis isolated from the western states of Nigeria using RAPD and AFLP. Indian J Microbiol 2010, 50(2):132-138.

11. Verdier V, Boher B, Maraite H, Geiger JP: Pathological and molecular characterization of Xanthomonas campestris isolates causing diseases of cassava (Manihot esculenta). Appl Environ Microb 1994, 60:4478-4486.

12. Verdier $V$, Dongo $P$, Boher B: Assessment of genetic diversity among strains of Xanthomonas campestris pv manihotis. J Gen Microbiol 1993, 139:2591-2601. 
13. Verdier V, Restrepo S, Mosquera G, Duque MC, Gerstl A, Laberry R: Genetic and pathogenic variation of Xanthomonas axonopodis pv. manihotis in Venezuela. Plant Pathol 1998, 47:601-608.

14. Restrepo S, Verdier V: Geographical differentiation of the population of Xanthomonas axonopodis pv. manihotis in Colombia. Appl Environ Microb 1997, 63(11):4427-4434.

15. Trujillo CA, Ochoa JC, Mideros MF, Restepo S, López C, Bernal A: A complex population structure of the Cassava Pathogen Xanthomonas axonopodis pv. manihotis in recent years in the Caribbean Region of Colombia. Microb Ecol 2014, 67(4). doi:10.1007/s00248-014-0411-8.

16. Restrepo S, Du que M, Tohme J, Verdier V: AFLP fingerprinting: an efficient technique for detecting genetic variation of Xanthomonas axonopodis pv. manihotis. Microbiology 1999, 145(Pt 1):107-114

17. Fillo S, Giordani F, Anniballi F, Gorge O, Ramisse V, Vergnaud G, Riehm JM, Scholz HC, Splettstoesser WD, Kieboom J, Olsen JS, Fenicia L, Lista F: Clostridium botulinum group I strain genotyping by 15 -locus multilocus variable-number tandem-repeat analysis. J Clin Microbio/ 2011, 49(12):4252-4263.

18. Blears MJ, De Grandis SA, Lee H, Trevors JT: Amplified fragment length polymorphism (AFLP): a review of the procedure and its applications. $J$ Ind Microbiol Biot 1998, 21:99-114.

19. Chiou CS: Multilocus variable-number tandem repeat analysis as a molecular tool for subtyping and phylogenetic analysis of bacterial pathogens. Expert Rev Mol Diagn 2010, 10(1):5-7.

20. Garcia-Yoldi D, Le Fleche P, De Miguel MJ, Munoz PM, Blasco JM, Cvetnic Z, Marin CM, Vergnaud G, Lopez-Goni I: Comparison of multiple-locus variable-number tandem-repeat analysis with other PCR-based methods for typing Brucella suis isolates. J Clin Microbiol 2007, 45(12):4070-4072.

21. Van Belkum A: Tracing isolates of bacterial species by multilocus variable number of tandem repeat analysis (MLVA). FEMS Immunol Med Mic 2007, 49(1):22-27.

22. Mazars E, Lesjean S, Banuls AL, Gilbert M, Vincent V, Gicquel B, Tibayrenc M, Locht C, Supply P: High-resolution minisatellite-based typing as a portable approach to global analysis of Mycobacterium tuberculosis molecular epidemiology. Proc Natl Acad Sci U S A 2001, 98(4):1901-1906.

23. Roring S, Scott A, Brittain D, Walker I, Hewinson G, Neill S, Skuce R: Development of variable-number tandem repeat typing of Mycobacterium bovis: comparison of results with those obtained by using existing exact tandem repeats and spoligotyping. J Clin Microbiol 2002, 40(6):2126-2133.

24. Keim P, Price LB, Klevytska AM, Smith KL, Schupp JM, Okinaka R, Jackson PJ, Hugh-Jones ME: Multiple-locus variable-number tandem repeat analysis reveals genetic relationships within Bacillus anthracis. J Bacterio/ 2000, 182(10):2928-2936

25. Melles DC, Schouls L, Francois P, Herzig S, Verbrugh HA, van Belkum A, Schrenzel J: High-throughput typing of Staphylococcus aureus by amplified fragment length polymorphism (AFLP) or multi-locus variable number of tandem repeat analysis (MLVA) reveals consistent strain relatedness. Eur J Clin Microbiol Infect Dis 2009, 28(1):39-45.

26. Coletta-Filho HD, Takita MA, de Souza AA, Aguilar-Vildoso Cl, Machado MA: Differentiation of strains of Xylella fastidiosa by a variable number of tandem repeat analysis. App/ Environ Microb 2001, 67(9):4091-4095.

27. Ngoc LB, Verniere C, Vital K, Guerin F, Gagnevin L, Brisse S, Ah-You N, Pruvost O: Development of 14 minisatellite markers for the citrus canker bacterium, Xanthomonas citri pv. citri. Mol Ecol Resour 2009, 9(1):125-127

28. N'Guessan CA, Brisse S, Le Roux-Nio AC, Poussier S, Kone D, Wicker E: Development of variable number of tandem repeats typing schemes for Ralstonia solanacearum, the agent of bacterial wilt, banana Moko disease and potato brown rot. J Microbiol Meth 2013, 92(3):366-374

29. Zhao S, Poulin L, Rodriguez RL, Serna NF, Liu SY, Wonni I, Szurek B, Verdier V, Leach JE, He YQ, Feng JX, Koebnik R: Development of a variable number of tandem repeats typing scheme for the bacterial rice pathogen Xanthomonas oryzae pv. oryzicola. Phytopathology 2012, 102(10):948-956.

30. Stevenson K, Alvarez J, Bakker D, Biet F, de Juan L, Denham S, Dimareli Z, Dohmann K, Gerlach GF, Heron I, Kopecna M, May L, Pavlik I, Sharp JM, Thibault VC, Willemsen P, Zadoks RN, Greig A: Occurrence of
Mycobacterium avium subspecies paratuberculosis across host species and European countries with evidence for transmission between wildlife and domestic ruminants. BMC Microbiol 2009, 9:212.

31. Pourcel C, Visca P, Afshar B, D'Arezzo S, Vergnaud G, Fry NK: Identification of variable-number tandem-repeat (VNTR) sequences in Legionella pneumophila and development of an optimized multiple-locus VNTR analysis typing scheme. J Clin Microbiol 2007, 45(4):1190-1199.

32. Castiblanco LF, Gil J, Rojas A, Osorio D, Gutierrez S, Munoz-Bodnar A Perez-Quintero AL, Koebnik R, Szurek B, Lopez C, Restrepo S, Verdier V, Bernal AJ: TALE1 from Xanthomonas axonopodis pv. manihotis acts as a transcriptional activator in plant cells and is important for pathogenicity in cassava plants. Mol Plant Pathol 2013, 14(1):84-95.

33. Verdier V, Mosquera G, Assigbétsé K: Detection of the Cassava bacterial blight pathogen, Xanthomonas axonopodis pv. manihotis, by Polymerase chain reaction. Plant Dis 1998, 82(1):79-83.

34. Vos P, Hogers R, Bleeker M, Reijans M, van de Lee T, Hornes M, Frijters A, Pot J, Peleman J, Kuiper M, Zabeau M: AFLP: a new technique for DNA fingerprinting. Nucleic Acids Res 1995, 23(21):4407-4414.

35. Hunter PR, Gaston MA: Numerical index of the discriminatory ability of typing systems: an application of Simpson's index of diversity. J Clin Microbiol 1988, 26(11):2465-2466.

36. Arrieta-Ortiz ML, Rodriguez-R LM, Pérez AL, Poulin L, Díaz AC, Arias Rojas N, Trujillo C, Restrepo-Benavides M, Bart R, Boch J, Boureau T, Darrasse A, David P, Bernonville TD, Fontanilla P, Gagnevin L, Guérin F, Jacques MA, Lauber E, Lefeuvre P, Medina C, Medina E, Montenegro N, Muñoz-Bodnar A, Noël L, Ortiz-Quiñones JF, Osorio D, Pardo C, Patil PB, Poussier S, et al: Genomic survey of pathogenicity determinants and VNTR markers in the cassava bacterial pathogen Xanthomonas axonopodis pv. manihotis strain CIO151. PLoS One 2013, 8(11):e79704.

37. Edgar RC: MUSCLE: multiple sequence alignment with high accuracy and high throughput. Nucleic Acids Res 2004, 32(5):1792-1797.

38. Peakall R, Smouse PE: GenAlEx 6.5: genetic analysis in Excel: population genetic software for teaching and research-an update. Bioinformatics 2012, 28(19):2537-2539.

39. Meirmans PG, Van-Tienderen PH: GENOTYPE and GENODIVE: two programs for the analysis of genetic diversity of asexual organisms. Mol Ecol Notes 2004, 4:792-794.

40. Huson DH, Bryant D: Application of phylogenetic networks in evolutionary studies. Mol Biol Evol 2006, 23(2):254-267.

41. Pritchard JK, Stephens M, Donnelly P: Inference of population structure using multilocus genotype data. Genetics 2000, 155(2):945-959.

42. Evanno G, Regnaut $\mathrm{S}$, Goudet J: Detecting the number of clusters of individuals using the software STRUCTURE: a simulation study. Mol ECOl 2005, 14(8):2611-2620.

43. Wright S: Genetical structure of populations. Nature 1950, 166(4215):247-249.

44. Bachem CW, van der Hoeven RS, de Bruijn SM, Vreugdenhil D, Zabeau M, Visser RG: Visualization of differential gene expression using a novel method of RNA fingerprinting based on AFLP: analysis of gene expression during potato tuber development. Plant J 1996, $9(5): 745-753$

45. Levinson G, Gutman GA: Slipped-strand mispairing: a major mechanism for DNA sequence evolution. Mol Biol Evol 1987, 4(3):203-221.

46. Torres-Cruz J, van der Woude MW: Slipped-strand mispairing can function as a phase variation mechanism in Escherichia coli. J Bacteriol 2003, 185(23):6990-6994.

47. Comas I, Homolka S, Niemann S, Gagneux S: Genotyping of genetically monomorphic bacteria: DNA sequencing in Mycobacterium tuberculosis highlights the limitations of current methodologies. PLoS One 2009, 4(11):e7815.

48. Aguilera Díaz M: La yuca en el Caribe colombiano: De cultivo ancestral a agroindustrial. In Documentos de trabajo sobre economía regional; http://www.banrep.gov.co/sites/default/files/publicaciones/archivos/ dtser 158.pdf: Banco de la República de Colombia 2012.

49. Lindstedt BA: Multiple-locus variable number tandem repeats analysis for genetic fingerprinting of pathogenic bacteria. Electrophoresis 2005 26(13):2567-2582.

50. Ramisse V, Houssu P, Hernandez E, Denoeud F, Hilaire V, Lisanti O, Ramisse F, Cavallo JD, Vergnaud G: Variable number of tandem repeats in Salmonella enterica subsp. enterica for typing purposes. J Clin Microbio/ 2004, 42(12):5722-5730. 
51. Chang $\mathrm{CH}$, Chang YC, Underwood A, Chiou CS, Kao CY: VNTRDB: a bacterial variable number tandem repeat locus database. Nucleic Acids Res 2007, 35(Database issue):D416-D421.

52. Bart R, Cohn M, Kassen A, McCallum EJ, Shybut M, Petriello A, Krasileva K, Dahlbeck D, Medina C, Alicai T, Kumar L, Moreira LM, Rodrigues-Neto J, Verdier V, Santana MA, Kositcharoenkul N, Vanderschuren H, Gruissem W, Bernal A, Staskawicz BJ: High-throughput genomic sequencing of cassava bacterial blight strains identifies conserved effectors to target for durable resistance. Proc Natl Acad Sci U S A 2012, 109(28):E1972-E1979.

doi:10.1186/1471-2180-14-161

Cite this article as: Trujillo et al:: Population typing of the causal agent of cassava bacterial blight in the Eastern Plains of Colombia using two types of molecular markers. BMC Microbiology 2014 14:161.

\section{Submit your next manuscript to BioMed Central and take full advantage of:}

- Convenient online submission

- Thorough peer review

- No space constraints or color figure charges

- Immediate publication on acceptance

- Inclusion in PubMed, CAS, Scopus and Google Scholar

- Research which is freely available for redistribution 